San Jose State University

SJSU ScholarWorks

Master's Theses

Master's Theses and Graduate Research

Spring 2018

\title{
Relationship between Aerobic Capacity and Episodic Memory in Older Adults
}

Nicole Henderson

San Jose State University

Follow this and additional works at: https://scholarworks.sjsu.edu/etd_theses

\section{Recommended Citation}

Henderson, Nicole, "Relationship between Aerobic Capacity and Episodic Memory in Older Adults" (2018). Master's Theses. 4907.

DOI: https://doi.org/10.31979/etd.b55z-6c9k

https://scholarworks.sjsu.edu/etd_theses/4907

This Thesis is brought to you for free and open access by the Master's Theses and Graduate Research at SJSU ScholarWorks. It has been accepted for inclusion in Master's Theses by an authorized administrator of SJSU ScholarWorks. For more information, please contact scholarworks@sjsu.edu. 


\title{
RELATIONSHIP BETWEEN AEROBIC CAPACITY AND EPISODIC MEMORY IN OLDER ADULTS
}

\author{
A Thesis \\ Presented to \\ The Faculty of the Department of Psychology \\ San José State University \\ In Partial Fulfillment \\ of the Requirements for the Degree \\ Master of Arts
}

by

Nicole Henderson

May 2018 
(C) 2018

Nicole Henderson

ALL RIGHTS RESERVED 
The Designated Thesis Committee Approves the Thesis Titled

\section{RELATIONSHIP BETWEEN AEROBIC CAPACITY AND EPISODIC MEMORY IN OLDER ADULTS}

by

Nicole Henderson

APPROVED FOR THE DEPARTMENT OF PSYCHOLOGY

SAN JOSÉ STATE UNIVERSITY

May 2018

$\begin{array}{ll}\text { Valerie Carr, Ph.D. } & \text { Department of Psychology } \\ \text { David Schuster, Ph.D. } & \text { Department of Psychology } \\ \text { Erin Woodhead, Ph.D. } & \text { Department of Psychology }\end{array}$ 


\section{ABSTRACT \\ RELATIONSHIP BETWEEN AEROBIC CAPACITY AND EPISODIC MEMORY IN OLDER ADULTS \\ by Nicole Henderson}

The goal of this research was to examine the relationship between aerobic capacity and memory in older adults. Prior research demonstrated an age-related decline in episodic memory (memory for episodes and events), which may be partially due to a decreasing ability to engage in pattern separation - the ability to form new memories that are sufficiently distinct from prior memories. Studies in rodents suggested that aerobic exercise may improve pattern separation abilities in older animals, but similar research in humans is lacking. Here, I investigated whether individual differences on a memory test that taxes pattern separation were associated with differences in aerobic capacity in 21 older adults aged 66-84 years old. Analyses indicate that memory performance was negatively associated with heart rate recorded during a fitness test, such that greater aerobic capacity (i.e., lower heart rate) was associated with better memory performance. This relationship held true regardless of task difficulty. However, when age was controlled for, this negative relationship was no longer significant. Additional analyses revealed that neither lifestyle factors such as lifetime physical activity or intake of healthy fats, nor depression symptoms, were related to memory performance. Given the limited sample size of this pilot study, caution is warranted in interpreting results. However, the promising relationship between aerobic capacity and memory performance may provide useful in informing future studies involving aerobic exercise interventions in older adults in an effort to improve episodic memory. 


\section{ACKNOWLEDGMENTS}

This thesis was a culmination of a lot of collaboration, guidance, and support from quite a few people. First, I'd like to thank my thesis advisor, Dr. Valerie Carr, who guided me through every step of the process with ease, keeping me calm, cool and collected at every juncture. Her experience in research and encouragement allowed me to grow as a researcher and learn valuable skills I will use for years to come. Also, thank you to my thesis defense committee Dr. Erin Woodhead and Dr. David Schuster. Dr. Erin Woodhead, who guided me through the clinical measures and Dr. David Schuster, who taught me how to provide meaningful results in psychological research using statistics.

Additionally, I’d like to thank Dr. Kasuen Mauldin, professor of nutrition, food science and packaging, and her graduate student Hilary Cole, without whom we could not have collected such extensive data on nutrition. It was a pleasure to collaborate with scientists from other departments and allowed us to examine variables we could not have otherwise explored. I’d also like to thank Dr. Peggy Plato, professor of exercise physiology, who’s guidance throughout the beginning stages of my research was imperative, helping me to explore fitness tests and measures of aerobic capacity for older adults. Also, my undergraduate research assistant Lucy Khuu, who did a lot of the legwork early in the research process, thank you Lucy!

Finally, I want to thank Isaac Aguilar, who supported me both emotionally and fiscally throughout this program. My mom, for always being there to listen. And to my participants, thank you for your time and effort. And to anyone I did not mention, thank you for reminding me to have fun and to continue working for what I want. 


\section{TABLE OF CONTENTS}

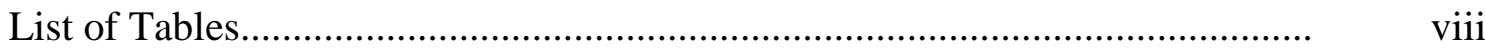

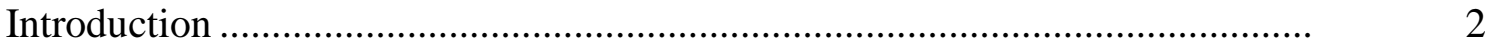

Aging and Memory ................................................................................

Factors Influencing Episodic Memory ..........................................................

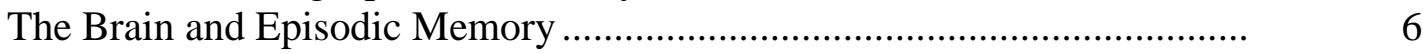

The Brain and Memory and Aging .............................................................

Exercise and Aging and Memory .................................................................

Current Study ....................................................................................

Participants ...........................................................................................

Measures and Stimuli ...........................................................................

Cognitive screening ...........................................................................

Depression assessment ......................................................................

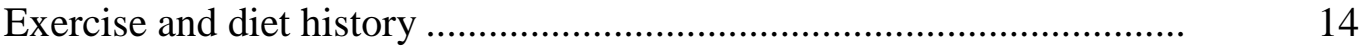

Mnemonic similarity task .................................................................... 15

Six-minute walk test .....................................................................

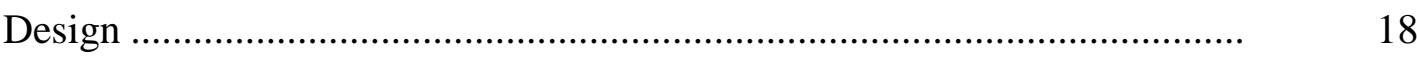

Statistical Analysis ......................................................................................

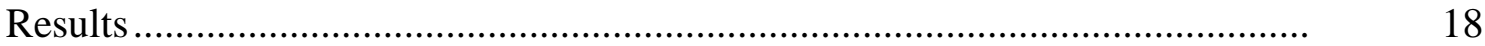

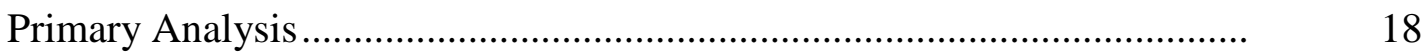

Follow-up Analysis .................................................................................. 21

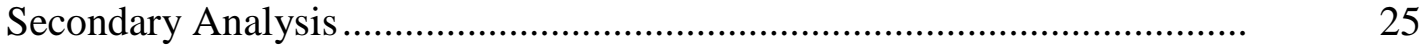

Discussion \& Future Research ..................................................................... 26

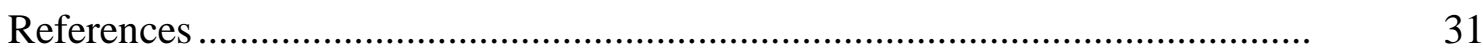




\section{LIST OF TABLES}

Table 1. Participant Characteristics........................................................... 18

Table 2. Relationship Between MST Performance and 6MWT Distance ......... 20

Table 3. Relationship Between MST Performance and 6MWT Steady State Heart Rate.................................................................................. 21

Table 4. Relationship Between MST Performance, 6MWT Distance, and Lure Similarity ................................................................................. 24

Table 5. Relationship Between MST Performance, 6MWT Steady State Heart Rate, and Lure Similarity .......................................................... 25

Table 6. Relationship between MST Performance, Lifetime Physical Activity, Depression Symptoms, and Fatty Acid Levels 


\section{LIST OF FIGURES}

Figure 1. $\quad$ MST timeline .................................................................... 16

Figure 2. Relationship between 6MWT distance and MST performance (LDI) 20

Figure 3. Relationship between steady state heart rate and MST performance (LDI)

Figure 4. Relationship between 6MWT distance and MST performance (LDI) according to lure similarity (lure bin) ..............................................

Figure 5. Relationship between 6MWT steady state heart rate in beats per minute (bpm) and MST performance (LDI) according to lure similarity (lure bin) 


\section{Introduction}

The Center for Disease Control and Prevention (2015a) reported that in the United States, the number of adults age 65 and older will more increase to about 71 million, by 2030. Considering the growing population of older adults, it will become increasingly important to study factors that influence cognition in aging and to identify and attempt to reduce age-related cognitive deficits. A number of studies have shown that as we age, episodic memory, our ability to recall events and episodes, becomes impaired (Cansino, 2009; Hedden \& Gabrieli, 2004; Old \& Naveh-Benjamin, 2008). Although multiple brain regions support episodic memory, the hippocampus is critically important in forming and subsequently retrieving episodic memories (Squire, Stark, \& Clark, 2004; Tulving \& Markowitsch, 1998), and it undergoes age-related atrophy and dysfunction (Hedden et al., 2004; Rosen et al., 2003). As such, changes in this region are thought to contribute in part to age-related decline in episodic memory.

Recent efforts to understand factors that may slow memory decline suggest that exercise may lead to both physical and cognitive benefits in older adults (Duzel, Praag, \& Sendtner, 2016). Specifically, researchers report better episodic memory performance in older adults who exercise than those who are sedentary (Chapman et al., 2013; Hayes et al., 2015; Maass et al., 2015), and, furthermore, have shown that hippocampal volume mediates the relationship between fitness levels and memory performance (Erickson et al., 2009). More recently, Varma and colleagues (2015) provided evidence that even lowintensity walking can increase hippocampal volume. Taken together, these results indicated that higher levels of physical fitness, particularly aerobic capacity, are linked to 
a better cognitive outcome in aging. However, it remains unclear whether and how aerobic capacity is related to memory processes supported specifically by the hippocampus, such as pattern separation. Pattern separation refers to the ability to form memory representations that are separable from similar, previously-formed memories. Furthermore, the degree to which pattern separation abilities are related to other measures of physical and cognitive health, such as diet, lifetime history of physical activity, and symptoms of depression, also remains underspecified. As such, the current study investigated whether individual differences in episodic memory are related to such factors.

\section{Aging and Memory}

Cognitive abilities decline with age; however, not all forms of cognition show agerelated change (Hedden et al., 2004). Episodic memory (memory for events), working memory (short-term maintenance and manipulation of information) and processing speed have been shown to decline with age (Park et al., 2002). Episodic memory is particularly vulnerable to age-related decline, especially the ability to recollect details about a particular episode (Old et al., 2008). The ability to encode and later retrieve rich, detailed memories is thought to rely on the hippocampal mechanisms of pattern separation and pattern completion (see, e.g., Norman \& O’Reilly, 2003; Yassa \& Stark, 2011). As noted above, pattern separation is defined as the ability to encode new episodic memories that are distinctly separate from similar, previously encoded memories. An example of pattern separation would be the ability to form a memory of this year's birthday celebration that is different from last year's birthday celebration. Pattern completion is the ability to 
retrieve a complete episodic memory based on a partial cue, for example, when a commercial for your favorite restaurant sparks the memory of your friends loudly singing happy birthday at this year's celebration.

To translate the hippocampal mechanism of pattern separation to human behavior, Stark and colleagues (Kirwan, Jones, Miller \& Stark, 2007) developed the Mnemonic Similarity Task (MST). During this computerized task participants viewed pictures of objects during the encoding phase, and immediately after, during the retrieval phase participants viewed an equal number of old items (identical to what they saw during encoding), new items (not seen during encoding), and similar lure items (objects similar to but not identical to what they saw at encoding). While viewing these pictures, participants were asked to judge whether each object is, "old”, "similar” or "new”. Yassa and colleagues (2011) used the MST to assess the ability of healthy younger and older adults to discriminate between old items and similar items, i.e., to form separable memory representations. They observed that compared to younger adults, healthy older adults were more likely to incorrectly label similar items as "old", which indicated that they had difficulty forming separable representations of items. This impaired discrimination ability suggests that hippocampal pattern separation may be impaired in healthy older relative to younger adults. Given that episodic memory, including pattern separation abilities, changes with age, researchers have become interested in investigating the factors that contribute to these changes. 


\section{Factors Influencing Episodic Memory}

Although episodic memory declines with age, there is substantial variability among individuals in the degree to which they experience such decline. This is due in part to the presence in some individuals of age-related diseases such as amnestic mild cognitive impairment (aMCI) or Alzheimer's disease (AD). aMCI is defined as a transitional stage between healthy aging and AD. Persons with aMCI have memory complaints and exhibit clinical memory impairments but show no signs of dementia and have preserved nonmemory cognitive abilities (Petersen et al., 2009). AD is distinct from aMCI in that, in addition to the memory complaints and impairments that mark aMCI, individuals with AD also meet criteria for dementia (Grundman et al., 2004).

Even among healthy individuals without an aMCI or AD diagnosis, there appears to be variability in episodic memory abilities (Hedden et al., 2004; Josefsson, Luna, Pudas, Nilsson \& Nyberg, 2012; Rapp \& Amaral, 1992; Stark, Yassa, Lacy \& Stark, 2013). Individual variability in episodic memory performance among healthy adults has been attributed to several lifestyle and genetic factors, including education, physical activity, social stimulation, APOع genotype (Christensen et al., 1999; Josefsson, et al., 2012), and the structure and function of the medial temporal lobe (MTL), including the hippocampus (Yassa et al., 2011).

\section{The Brain and Episodic Memory}

Based on decades of lesion studies in both humans and other animals, research indicates that there are multiple memory systems in the brain (Squire et al., 2004). That is, there is more than one type of memory, and these different forms of memory depend 
upon different regions of the brain. Studies of memory deficits following MTL lesions indicated that this area of the brain is critical for declarative memory, which refers to long-term memory for events (episodic memory) and facts (semantic memory; Squire et al., 2004). The development of functional magnetic resonance imaging (fMRI) in the 1990s allowed researchers to study the function of this region in healthy individuals and not simply in those with lesions. More recently, researchers have begun using highresolution fMRI to explore activity in individual subregions within the MTL, with evidence to date suggesting that these subregions play unique roles in supporting declarative memory (Carr, Rissman \& Wagner, 2010). The hippocampus, a subregion of the MTL, receives inputs from adjacent cortical structures representing multiple sensory modalities, and thus is thought to play a role in binding together individual elements of an event into a single cohesive episodic memory (Squire et al., 2004).

The hippocampus itself can be further broken down into several subfields, including cornu ammonis 1, 2, and 3 (CA1, CA2, and CA3); the dentate gyrus (DG); and the subiculum. Additionally, these subfields have unique anatomy and connectivity, leading to differences in their functional role in episodic memory (Carr, et al., 2010). Specifically, pattern separation processes are thought to depend largely upon DG and its sparse connectivity with CA3. Within CA3, recurrent connections are thought to allow for the binding of multimodal inputs into a single representation. Subsequently, when a partial cue is presented, CA3 is thought to pattern complete the previously encoded representation; this retrieved information then projects back to the cortex via CA1 and the subiculum (Treves, Tashiro, Witter \& Moser, 2008). Importantly, in addition to playing 
separate roles in episodic memory, subregions of the MTL are also differentially affected by aging and age-related diseases.

\section{The Brain and Memory and Aging}

Studies in rodents and humans have demonstrated changes in MTL function with age, but these changes are not widespread (Leal \& Yassa, 2015). Rodent studies, for example, have shown weakened synaptic inputs from the cortex to DG and CA3 and fewer inhibitory neurons in these regions (Wilson, Gallagher, Eichenbaum \& Tanila, 2006), leading to hyper-excitability and memory impairments. Neuroimaging studies in humans have shown similar results, with older adults showing greater DG/CA3 activity while performing the MST than younger adults (Yassa et al., 2011), as well as worse performance on the task itself - thus suggesting an impairment in pattern separation abilities.

In addition to the abovementioned age-related changes to the DG, this region also shows a decline in adult neurogenesis with age. Adult neurogenesis, or the birth of new neurons after development, occurs in a very limited number of brain regions, including the DG (Yassa et al., 2011). Adult-born hippocampal neurons contribute to cognitive plasticity (Christian, Song \& Ming, 2014), and evidence from animal models suggests a mediating role for newborn DG neurons in pattern separation (Sahay, Wilson \& Hen, 2011). Spalding and colleagues (2013) found that there is a moderate age-related decrease in hippocampal neurogenesis in humans. For this reason, it is theorized that dysfunction of the DG and impairments in pattern separation with age may be related to a decrease in neurogenesis. 
Additionally, evidence suggested that when neurogenesis is chemically and genetically decreased in mice, performance on tasks designed to tax pattern separation is impaired, whereas other episodic-related memory tasks such as object recognition, spatial learning, and contextual fear conditioning are not affected (Sahay et al., 2011). Supporting this notion, Nakashiba and colleagues (2012) found that damage to newborn DG cells was associated with a decrease in pattern separation performance, but when older DG cells were damaged, pattern completion performance decreased, suggesting that as DG cells age, their role in supporting episodic memory switches from pattern separation to pattern completion. Combined, these results indicate that a decline in neurogenesis with age contributes to DG dysfunction, and in turn, to difficulties with pattern separation. Importantly, however, a variety of factors can regulate neurogenesis, including neurotrophins like brain-derived neurotrophic factor (BDNF) and insulin-like growth factor (IGF), as well as exercise (Déry et al., 2013).

\section{Exercise and Aging and Memory}

The body's short-term response to exercise includes increased heart rate, increased blood flow to the muscles to provide oxygen, deeper breathing, and sweating to regulate temperature. Long-term responses include increases in testosterone, cortisol, metabolism, BDNF, and hypertrophy induced by IGF release (Biagioli, 2007). Benefits of exercise include improvements in functional ability, mental health, physical health (including musculoskeletal health, body weight, metabolic health, and cardiorespiratory health), and a reduction of the risk of Alzheimer’s disease (Radak et al., 2010; U.S. Department of Health and Human services, 2008). 
Reviews of individual differences in cognition in older adults suggest that higher amounts of aerobic exercise are associated with better memory (Hedden et al., 2004; Josefsson et al., 2012). There are many changes in the brain that may underlie the beneficial effects of exercise on memory, including increased hippocampal volume (Erickson et al., 2009; ten Brinke et al., 2014), increased cortical plasticity (Colcombe et al., 2004; Maass et al., 2015), and increased BDNF (Griffin et al., 2011). Exercise has also been linked to reduced hippocampal atrophy in older adults with genetic risk for $\mathrm{AD}$ (Smith et al., 2014).

With respect to changes in the hippocampus induced by exercise, studies of adult male rats indicated that aerobic exercise such as running promotes adult neurogenesis (Nokia et al., 2016). Studies of running mice indicated that aerobic exercise improves performance on tasks that stress pattern separation abilities, including spatial discrimination tasks (Creer et al., 2010) and object recognition tasks (Bolz, Heigele \& Bischofberger, 2015). These results suggest that exercise may be particularly beneficial for pattern separation. Recently, Déry and colleagues (2013) investigated the relationship between exercise and a memory task that taxed pattern separation in young adult humans. The authors found that young adults who improved their fitness level by exercising performed better on the task than those who did not exercise. However, their sample size was fairly small, used younger adults, and the task used was adapted from the original MST and therefore needs to be further validated.

When examining the relationship between physical fitness and hippocampal function in older adults, it is important to not only consider current levels of fitness, but lifetime 
history of physical activity as well. Recent studies in rodents, for example, indicate that animals who exercised early in life had more memory-related neuronal activity in old age compared to those who did not (Shevtsova et al., 2017). In humans, a recent study by Maass et al. (2015) examined the effects of exercise on a memory task designed to stress pattern separation failed to find a time $\mathrm{x}$ group interaction, due to the control group having a more active lifestyle at baseline. Another human study found a relationship between processing speed in older age and early physical activity (Dik, Deeg, Visser, \& Jonker, 2003). These results indicated that to accurately understand the relationship between pattern separation abilities and current physical fitness, one must control for lifetime fitness levels as well.

It bears noting that most studies assessing the relationship between exercise, the brain, and memory have examined aerobic exercise (Erickson et al., 2009; ten Brinke et al., 2014; Colcombe et al., 2004; Maass et al., 2015; Griffin et al., 2011; Varma, Chuang, Harris \& Carlson, 2015; Weuve et al., 2004). A smaller number of studies have investigated resistance exercise, which involves the use of body weight or resistance from other sources to maintain and/or build strength in the muscles (e.g., Center for disease control and prevention, 2015b). This form of exercise has been linked to positive effects in aging, including improved cognitive function in humans and hippocampal-dependent memory in rats (Cassilhas et al., 2007; Cassilhas et al., 2012). It is also important to note that, regardless of the type of exercise being examined, the studies mentioned above typically use spatial memory tasks, simple tests of item memory, or standardized neuropsychological tests of memory. Thus, the degree to which exercise in humans may 
improve performance on tasks that specifically tax hippocampal pattern separation remains unclear.

Importantly, exercise is not the only factor that may influence one's physical and cognitive health. Studies looking at dietary intake suggested that nutritional adequacy in one's diet is positively correlated with memory and overall cognition in older adults (Beydoun et al., 2014). Additionally, rodent studies have found that certain omega-3 fatty acids are neuroprotective (Miao-Miao et al., 2016). Symptoms of depression, on the other hand, have been associated with poor performance on the MST in older adults (Shelton \& Kirwan, 2013) and impairments in autobiographical memory (Williams et al., 2007).

Similarly, MRI studies in older adults indicated that depressed individuals have significantly more atrophy of the hippocampus and show significantly more signs of cognitive decline (i.e. memory loss) compared to healthy controls (Elbejjani et al., 2015; Shimada et al., 2014).

\section{Current Study}

The current study aimed to bridge the gap between (1) animal studies of hippocampal pattern separation and (2) studies in humans examining the relationship between physical fitness and more generalized tests of memory. I addressed this issue by assessing episodic memory via the MST, for which optimal performance requires the ability to form separable memory representations. I then examined whether individual differences in performance on this task are related to differences in aerobic capacity as assessed by performance on the Six Minute Walk Test (6MWT). 
I hypothesized that I would find a positive relationship between MST performance and 6MWT performance, such that older adults with greater aerobic capacity would perform better on the MST than individuals with lower aerobic capacity. More specifically, I predicted that those with greater aerobic capacity would correctly identify similar lures as "similar" more frequently than those with lower aerobic capacity, who would be more prone to incorrectly identifying similar lures as "old."

Using the MST, Yassa et. al (2011) have shown that, relative to younger adults, older adults require greater dissimilarity between studied items and similar lures in order to correctly identify lures as "similar" rather than "old.” For example, an older adult would likely incorrectly identify a vase of red roses as "old" if it is highly similar to a previously-studied vase of red roses but would easily identify a vase of white roses as being "similar" to, but different from, a previously-studied vase of red roses. Motivated by this finding, I hypothesized that I would find an interaction between aerobic capacity and task difficulty, such that there would be a clear relationship between aerobic capacity and memory performance on difficult trials, in which participants are required to discriminate between highly similar items, but that aerobic capacity would not relate to memory performance on easy trials.

Variation in MST performance may also relate to individual differences in lifetime physical activity, diet, and depression symptoms. I predicted that both lifetime physical activity levels and degree of omega-3 fatty acid consumption would be positively associated with MST performance. Conversely, I predicted that depression symptoms would be negatively associated with MST performance. 


\section{Method}

\section{Participants}

Volunteers between the ages of 65 and 89 were recruited from local community centers, independent living centers, and newspaper ads in the San Jose Mercury News. Individuals expressing interest in the study were screened by phone to be sure they met the inclusion criteria and did not meet exclusion criteria. Specifically, I excluded participants who were not eligible to participate in physical activity (required during the 6MWT) due to health concerns based on the American College of Sports Medicine (ACSM) recommendations (Riebe et al., 2015). The phone screen also included questions designed to exclude participants who have any conditions that could affect their cognition including AD, Parkinson’s, multiple sclerosis (MS), epilepsy, or a psychiatric disorder (e.g., schizophrenia). Finally, participants were encouraged to seek approval from their doctor to engage in exercise before taking part in the study.

A total of twenty-six participants 66 - 84 years of age, enrolled in the study $(M=74$, $S D=5.7,12$ female, 14 male). Five participants were excluded due to performing poorly on an assessment used to screen for cognitive impairment, leaving 21 participants 66 - 84 years of age who participated in the full study $(M=74, S D=5.2,10$ female, 11 male). Heart rate data for the 6MWT are not included for two participants due to equipment malfunction.

All participants provided informed consent in accordance with a protocol approved by San José State University and were compensated \$10/hr for their participation. 


\section{Measures and Stimuli}

Cognitive screening. Following the consent procedure, participants’ overall cognitive health was screened with the Montreal Cognitive Assessment (MoCA; Nasreddine et al., 2005) to ensure that they did not meet exclusion criteria. The MoCA is a one page, 30-item test that takes approximately 10 minutes and involves tests of several cognitive abilities including short term memory, visuospatial abilities, executive function, language, and recall. Those who scored lower than a 26 were excluded based on previous research demonstrating that the ideal balance between specificity and detection of cognitive impairment occurs at this cutoff score (Nasreddine et al., 2005).

Depression assessment. To measure depressive symptoms, participants were asked to complete the short form of the Geriatric Depression Scale, which provides a score ranging from 0 to 15, with scores above 4 indicating mild to severe depression (Yesavage \& Sheikh, 1986). The GDS score was used in a regression analysis to determine whether depression symptoms are negatively associated with memory performance.

Exercise and diet history. Next, participants completed the NutritionQuest BLOCK Food Frequency Questionnaire (FFQ; Block, Hartman, Faktor \& Warburton, 1986) to assess their eating habits in the last month. From the FFQ, I determined the levels of two omega-3 fatty acids in the diet, DHA and EPA, the summation of which was used in a regression analysis to determine whether fatty acid consumption is positively associated with memory performance.

To assess lifetime physical activity, I used an adapted version of the Lifetime Physical Activity Questionnaire (Chasan-Taber et al., 2002). The original version 
calculates the amount of time spent doing various physical activities (e.g., running, biking, etc.) on a weekly basis during each decade of life (teens, twenties, thirties, etc.). For the purposes of this study, I adapted the scoring procedure to produce an overall categorical measure of lifetime physical activity (inactive, relatively inactive, relatively active, extremely active) rather than a measure for each individual activity. This categorical information was used in a regression analysis to determine whether lifetime physical activity is positively associated with memory performance.

Mnemonic similarity task (MST). The MST (Kirwan et al., 2007) is a computerized memory task that consists of two phases: encoding and retrieval (Figure 1). During encoding, participants were asked to make a simple decision regarding each stimulus to help maintain attention. Specifically, participants were shown 128 pictures of common objects and asked to decide whether these objects are typically found indoors or outdoors. Immediately following encoding, participants were given instructions for the retrieval phase. During retrieval, participants again viewed pictures of common objects, 64 of which were targets (seen during encoding), 64 were novel (not seen during encoding), and 64 were similar lures (items similar to those seen during encoding), for a total of 192 items. Stimuli were presented for 2 seconds each with a 0.5 second inter-stimulus interval during both encoding and retrieval. In response to each item, participants were asked to respond "old”, "similar”, or "new." 


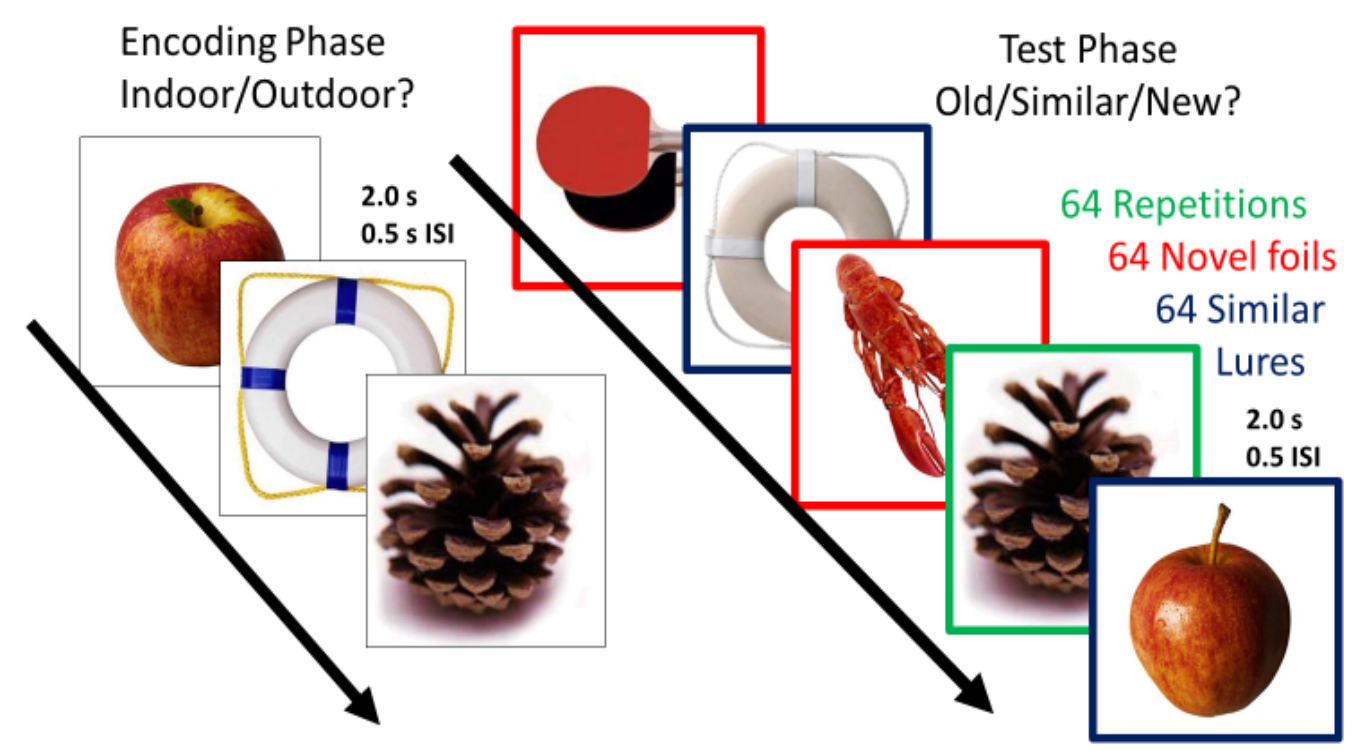

Figure 1. MST timeline, encoding (128 household items) and retrieval (64 repetition, i.e. targets, 64 novel, i.e. new, 64 lures, i.e. similar items), participants respond "old" "similar" or "new".

Per prior studies employing the MST (e.g., Lacy, Yassa, Stark, Muftuler, \& Stark, 2011; Yassa et al., 2011; Stark, et al., 2013), performance on the MST was assessed via lure discrimination index (LDI). LDI is calculated as the difference between the rate at which participants correctly responded "similar" to lures and the rate at which they incorrectly responded "similar” to new items (“similar”|lure - "similar”|new).

Importantly, similar lure items vary in similarity to items presented during encoding, with level 1 (L1) being most similar and level 5 (L5) being least similar to originallyencoded items. Prior research demonstrated that participants were more likely to incorrectly identify L1 lures as “old” than L5 lures, the latter of which were most often correctly identified as “similar” (Yassa et al., 2011). Motivated by these findings, for a 
subset of analyses, I calculated LDI separately for high similarity trials (L1 and L2) and low similarity trials (L4 and L5).

Six-minute walk test. The 6MWT is a test of aerobic capacity that is self-paced and specifically tailored to older adults (Burr, Bredin, Faktor \& Warburton, 2011).

Participants were asked to walk down a $30 \mathrm{~m}$ (100 ft) pathway and to briskly turn around cones placed at each end. They were instructed to walk around the cones as many times as possible for six minutes but not to jog or run and were given scripted encouragement throughout. Resting blood pressure and heart rate were measured before and after the test to ensure that participants returned to resting state prior to leaving the lab. In addition, a pulse oximeter was used throughout the duration of the test to measure pulse (heart rate during exercise) and peripheral capillary saturation $\left(\mathrm{SpO}^{2}\right)$, the latter which was used to estimate the amount of oxygen in the blood and as a safety criterion for terminating the test if necessary. Two metrics were used to gauge aerobic capacity based on this test: (1) distance walked, and (2) steady-state heart rate during exercise (measured by taking the average heart rate during the middle 4 minutes of the test). Ranges, means, and standard deviations for all metrics described above can be found in Table 1. 
Table 1

Participant Characteristics

\begin{tabular}{llll}
\hline Measure & Interval (Possible Interval) & $M$ & $S D$ \\
\hline Age (years) & $66-84$ & 74 & 5 \\
MST performance (LDI) \% & $-5.33-57.73(-100 \%-100 \%)$ & 25.82 & 18.50 \\
Height (inches) & $62.5-73.0$ & 66.3 & 2.9 \\
Healthy Fats (average grams per day) & $0.016-0.471$ & 0.12 & 0.10 \\
GDS score & $0-4(0-15)$ & 0.9 & 1.12 \\
6MWT Distance (feet) & $1180-2200$ & 1747.5 & 284.9 \\
6MWT Steady state heart rate (beats & $66.88-151.68$ & 99.37 & 22.22 \\
per minute) & & & \\
\hline
\end{tabular}

Note. MST = Mnemonic Similarity Task, LDI = lure discrimination index, 6MWT = Six-minute walk test, $\mathrm{M}=$ mean, $\mathrm{SD}=$ standard deviation

\section{Design}

The primary purpose of this study was to determine whether individual differences in performance on the MST can be explained, in part, by differences in aerobic capacity as assessed by the 6MWT. Of secondary interest was whether variability in lifetime physical fitness, diet, and depression symptoms also relates to variability in MST performance.

\section{Statistical Analysis}

Multiple linear regression and data visualization were performed using custom code that employed the Hmisc, psych, MASS, ggplot2, and ez libraries in R (https://cran.rproject.org) and the pandas, stats, matplotlib, and seaborn libraries in Python (https://www.python.org). 


\section{Results}

\section{Primary Analyses}

The overarching goal of this study was to investigate the relationship between aerobic capacity and performance on an episodic memory task designed to tax pattern separation. As such, I performed a multiple linear regression to assess whether individual differences in MST performance (measured via LDI) are associated with individual differences in 6MWT distance while controlling for age and height. Height was included as a control variable because taller individuals typically have longer stride lengths, and thus walk further than shorter individuals independent of actual fitness level. Results indicate that the model was not significant, such that variance in MST performance was not accounted for by variance in the predictive variables $\left(R^{2}=0.188\right.$, Adj $R^{2}=0.045, F(3,17)=1.311$, $p=0.303$; see Table 2). Although the model was not significant overall, the results were in the expected direction, such that there was a non-significant positive association between 6MWT distance and MST performance. A follow-up analysis directly testing the relationship between 6MWT distance and LDI revealed a non-significant positive correlation between the two measures. $(r=0.42, p=0.077)$; see Figure 2 . 
Table 2

Relationship Between MST Performance and 6MWT Distance

\begin{tabular}{llccc}
\hline Variable Name & $\beta$ & $S E$ & $t$ & $p$ \\
\hline 6MWT Distance & 0.447 & 0.245 & 1.82 & 0.086 \\
Height & -0.263 & 0.233 & -1.13 & 0.274 \\
Age & 0.001 & 0.232 & 0.044 & 0.965 \\
\hline
\end{tabular}

Note. MST = Mnemonic Similarity Task, 6MWT = Six-minute walk test, $S E=$ standard error.

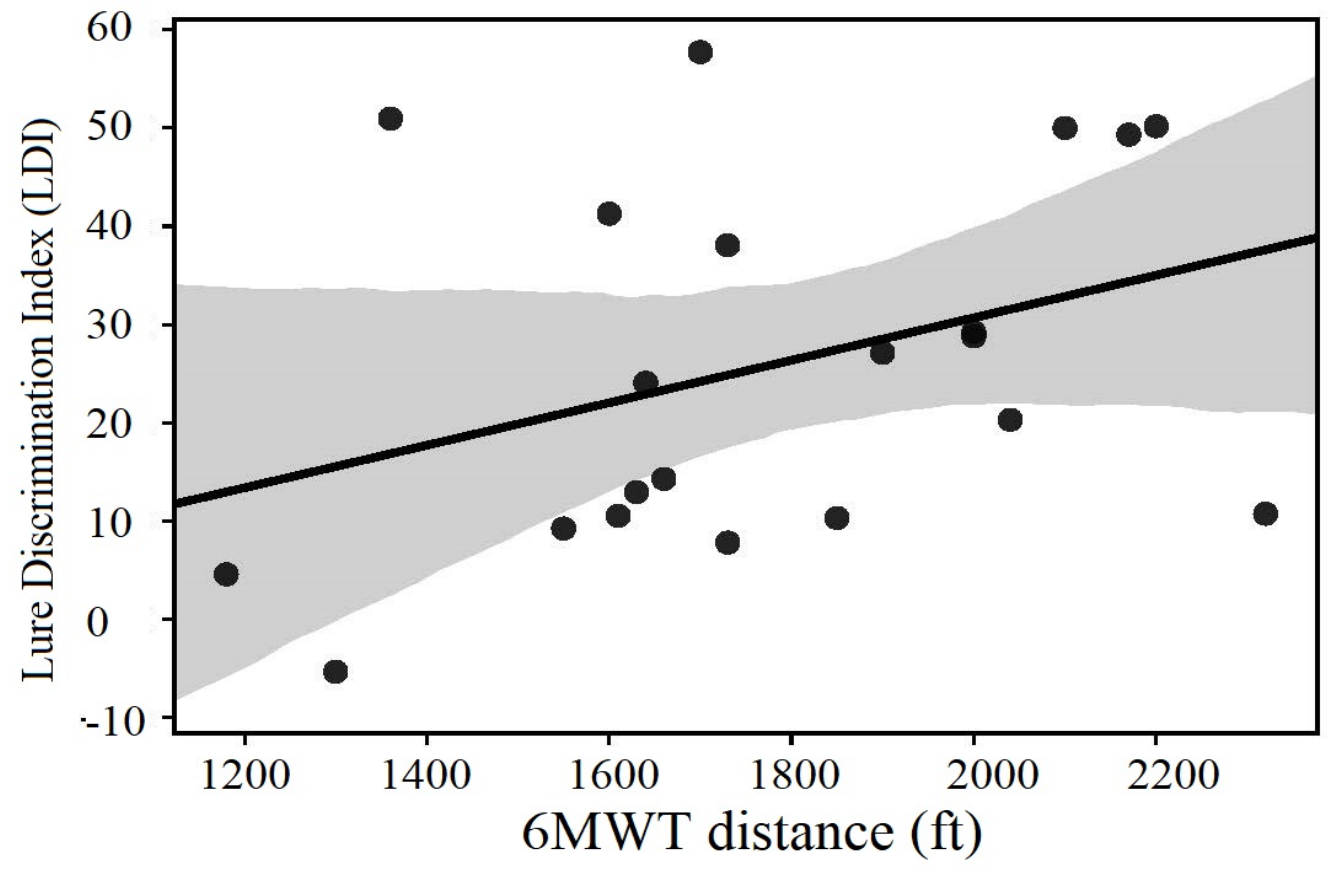

Figure 2. Relationship between 6MWT distance in feet (ft) and MST performance (LDI). Note, LDI = p(“similar”|lure $)-p($ “similar”|new).

To complement the regression above that used 6MWT distance as the metric of aerobic capacity, I repeated this analysis using 6MWT steady state heart rate instead, while also controlling for age. Results indicate that although the overall model fit was not 
significant, results were in the expected direction $\left(R^{2}=0.278\right.$, Adj $R^{2}=0.189, F(2,16)=$ 3.092, $p=0.073$; see Table 3), such that the lower the heart rate, the better the task performance. A follow-up analysis directly testing the relationship between 6MWT steady state heart rate and LDI revealed a significant negative correlation between the two measures. $(r=-0.52, p=0.023)$; see Figure 3 .

Table 3

Relationship Between MST Performance and 6MWT Steady State Heart Rate

\begin{tabular}{lcccc}
\hline Variable Name & $\beta$ & $S E$ & $t$ & $p$ \\
\hline 6MWT steady state & -0.523 & 0.213 & -2.46 & $0.0255^{*}$ \\
Age & 0.102 & 0.213 & 0.478 & 0.639 \\
\hline
\end{tabular}

Note. MST $=$ Mnemonic Similarity Task, $6 \mathrm{MWT}=$ Six-minute walk test, $\mathrm{SE}=$ standard error, ${ }^{*} \mathrm{p}<.05$

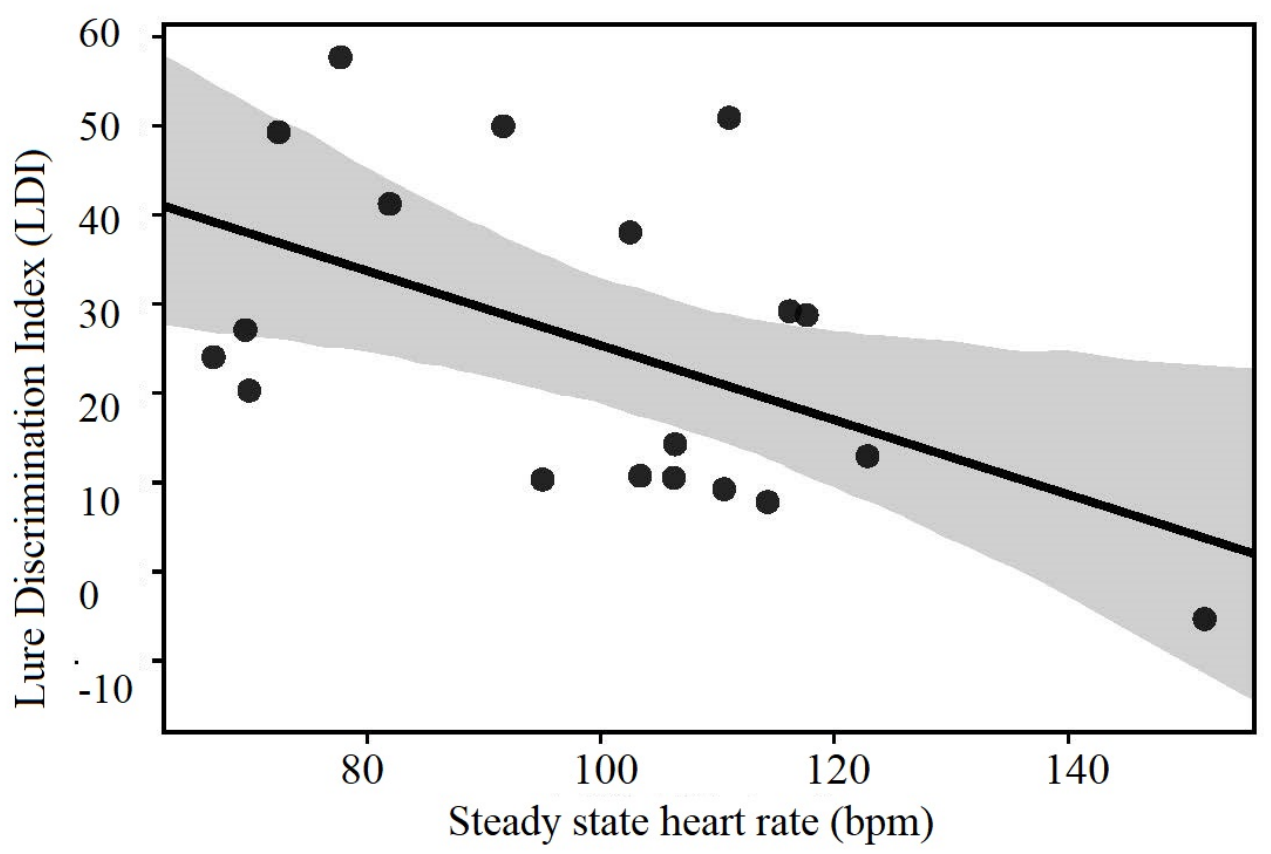

Figure 3. Relationship between steady state heart rate (beats per minute - bpm) and MST performance (LDI). Note. LDI = p(“similar”|lure) - p(“similar”|new). 


\section{Follow-up Analyses}

In addition to investigating the relationship between aerobic capacity and memory performance overall, I also performed follow-up analyses examining memory performance separately for more difficult trials (involving discrimination between highly similar items) and less difficult trials (involving discrimination between items with low similarity). Specifically, I was interested in whether the relationship between aerobic capacity and memory performance found above was stronger when task difficulty (i.e., lure similarity) was high than when it was low. Specifically, I used multiple linear regression to investigate the extent to which the relationship between aerobic capacity and task performance depends on lure similarity (see Methods), such that the model included these two predictor variables, as well as the interaction between them.

First, using 6MWT distance as a measure of aerobic capacity, results indicate that the overall model fit was significant, such that variance in the predictive variables accounted for a significant amount of variance in MST performance $\left(R^{2}=0.279\right.$, Adj $R^{2}=0.222, F$ $(3,38)=4.90, p=0.005$; see Table 4). Specifically, 6MWT distance was positively associated with MST performance when controlling for lure similarity and the interaction between 6MWT distance and lure similarity, such that the greater the distance participants walked, the better their performance on the task. As expected, lure similarity was negatively associated with MST performance when controlling for 6MWT distance and the interaction between 6MWT distance and lure similarity, such that performance was worse for highly similar items than for less similar items. However, there was not a significant interaction between these two metrics, such that the positive relationship 
between 6MWT distance and MST performance held true regardless of lure similarity (see Figure 4). 
Table 4.

Relationship Between MST Performance, 6MWT Distance, and Lure Similarity

\begin{tabular}{lcccc}
\hline Variable Name & $\beta$ & $S E$ & $t$ & $p$ \\
\hline 6MWT distance & 0.314 & 0.137 & 2.284 & $0.028^{*}$ \\
Lure Bin & -0.416 & 0.136 & -3.06 & $0.004^{* *}$ \\
6MWT distance * Lure Bin & 0.047 & 0.138 & 0.341 & 0.735
\end{tabular}

Note. MST = Mnemonic Similarity Task, 6MWT = Six-minute walk test, $S E=$ standard error, ${ }^{*} p<0.05,{ }^{* *} p<0.01$, Lure similarity $=$ High (lure bins $1 \& 2$ ), Low (lure bins 4 \& 5)

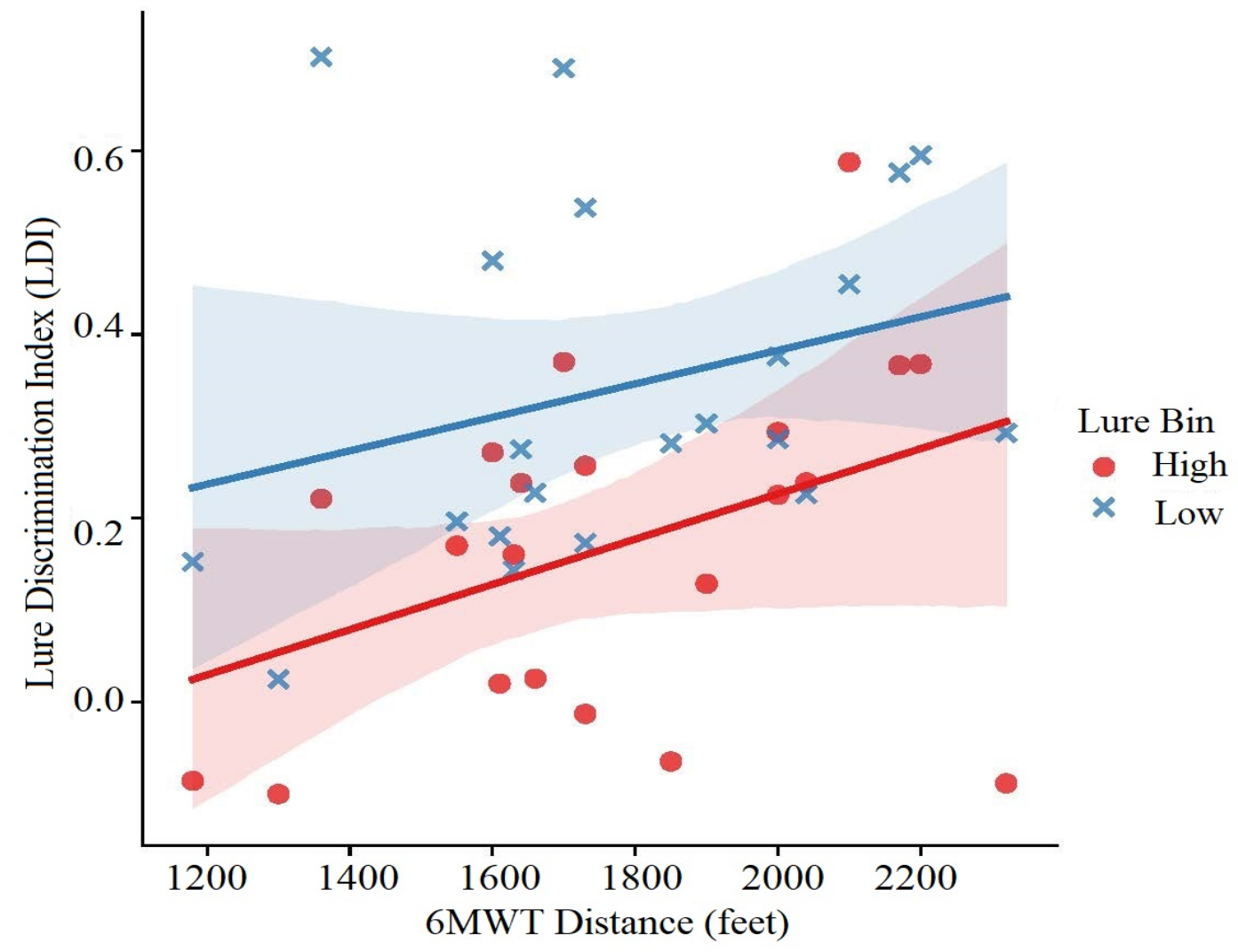

Figure 4. Relationship between 6MWT distance and MST performance (LDI) according to lure similarity (lure bin). Note, LDI = p(“similar”|lure) p(“similar"|new) for each lure bin. High lure bin = L1 and L2 averaged LDI, low lure bin = L4 and L5 averaged LDI. 
To complement the analysis above that used 6MWT distance as a measure of aerobic capacity, I repeated this analysis instead using 6MWT steady state heart rate as a measure of aerobic capacity. Results revealed that variance in the predictive variables accounted for a significant amount of variance in MST performance $\left(R^{2}=0.342\right.$, Adj $R^{2}=0.283, F$ $(3,34)=5.88, p=0.002$; see Table 5). Specifically, 6MWT steady state heart rate was negatively associated with MST performance when controlling for lure similarity and the interaction between heart rate and lure similarity, such that the lower the heart rate (and thus greater the aerobic capacity), the better their performance on the task. As expected, lure similarity was negatively associated with MST performance when controlling for heart rate and the interaction between heart rate and lure similarity, such that performance was worse for highly similar items than for less similar items. However, there was not a significant interaction between these two metrics, such that the negative relationship between 6MWT steady state heart rate and MST performance held true regardless of lure similarity; see Figure 5.

Table 5.

Relationship Between MST Performance, 6MWT Steady State Heart Rate, and Lure Similarity

\begin{tabular}{lcccc}
\hline Variable Name & $\beta$ & $S E$ & $t$ & $p$ \\
\hline 6MWT Steady State HR & -0.409 & 0.139 & -2.94 & $0.006^{* *}$ \\
Lure Bin & -0.412 & 0.137 & -3.00 & $0.005^{* *}$ \\
6MWT HR * Lure Bin & 0.0018 & 0.139 & 0.013 & 0.989 \\
\hline
\end{tabular}

Note. MST = Mnemonic Similarity Task, 6MWT $=$ Six-minute walk test, $S E=$ standard error, $* p<0.05,{ }^{* *} p<0.01$, Lure similarity $=$ High (lure bins $1 \& 2$ ), Low (lure bins $4 \& 5$ ) 


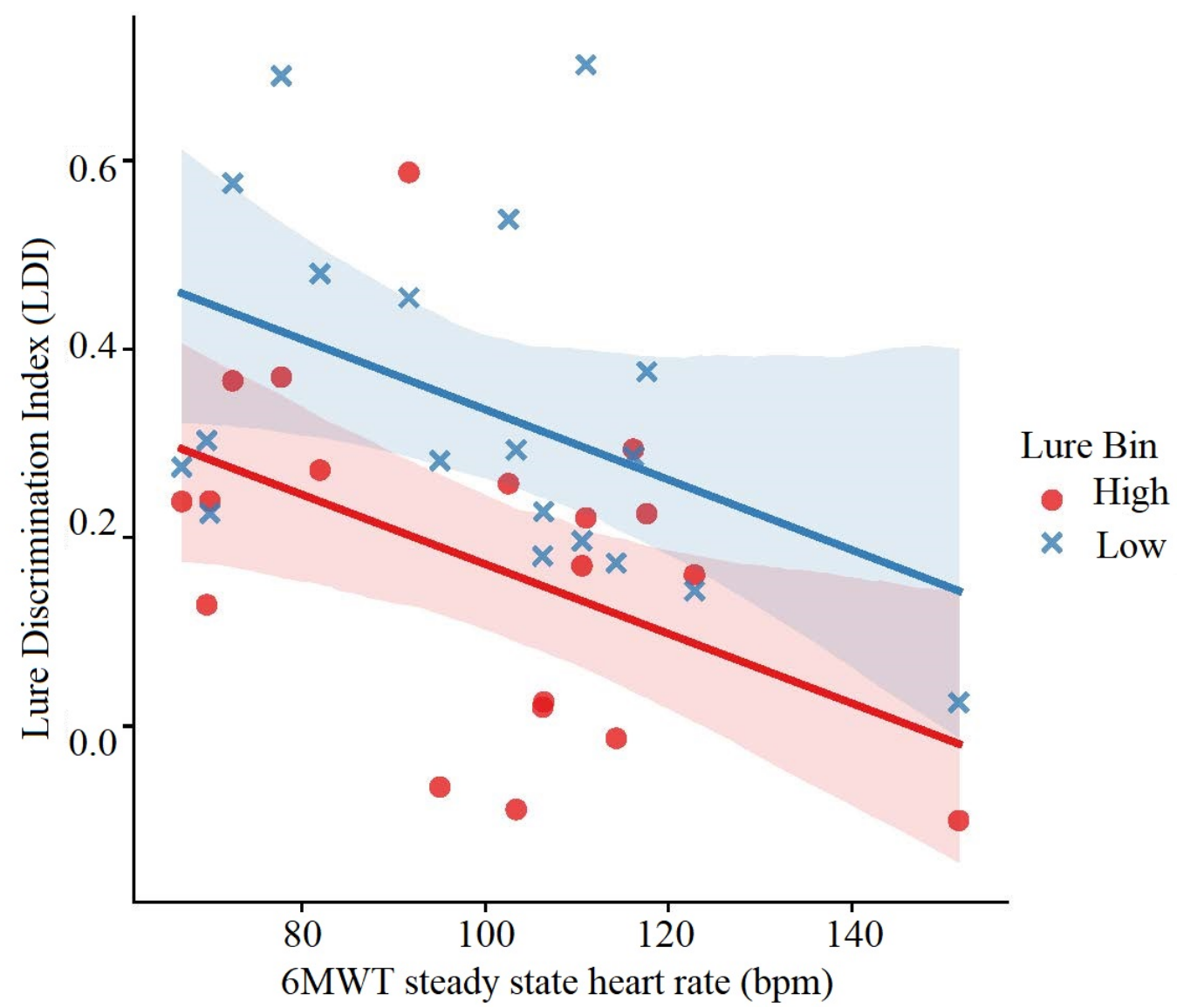

Figure 5. Relationship between 6MWT steady state heart rate in beats per minute (bpm) and MST performance (LDI) according to lure similarity (lure bin). Note, LDI = p(“similar”|lure) - p(“similar”|new) for each lure bin. High lure bin = L1 and L2 averaged LDI scores. Low lure bin = L4 and L5 averaged LDI scores.

\section{Secondary Analysis}

In addition to investigating the relationship between MST performance and 6MWT distance/heart rate, I also used multiple linear regression to investigate the degree to which variability in lifetime exercise history, depression symptoms, and fatty acid levels contribute to individual differences in MST performance. Results indicate that the model was not significant, such that variability in MST performance 
was not significantly accounted for by variability in the predictive variables $\left(R^{2}=\right.$ 0.169, Adj $R^{2}=0.022, F(3,17)=1.151, p=0.357$; see Table 6$)$.

Table 6.

Relationship between MST Performance, Lifetime Physical Activity, Depression Symptoms, and Fatty Acid Levels

\begin{tabular}{lcccc}
\hline Variable Name & $\beta$ & $S E$ & $t$ & $p$ \\
\hline Lifetime activity & -0.328 & 0.235 & -1.39 & 0.182 \\
Depression symptoms & -0.353 & 0.249 & -1.42 & 0.175 \\
Fatty acids & -0.057 & 0.253 & -0.230 & 0.825 \\
\hline
\end{tabular}

Note. MST = Mnemonic Similarity Task, SE = standard error 


\section{Discussion \& Future Research}

The results of this study suggest that there is a positive relationship between current levels of aerobic capacity and performance on a test of episodic memory that taxes pattern separation, such that older adults who are more aerobically fit (specifically, those with a lower steady state heart rate during exercise) perform better on this test. Interestingly, this relationship held true regardless of task difficulty, such that older adults who are more fit performed better on trials requiring discrimination between either highly similar items or items with low similarity. However, when analyses included age as a control variable, the relationship between aerobic capacity and memory performance was no longer significant. Finally, secondary analyses revealed that neither lifestyle factors such as lifetime physical activity or intake of healthy fats, nor depression symptoms, were related to memory performance.

To better understand why including age as a control variable affected the significance of the relationship between aerobic capacity and MST performance, I first evaluated whether collinearity between 6MWT steady state heart rate and age may be an issue. Correlation analysis revealed that these two measures were not significantly related ( $r=$ $0.05, p=0.83$ ), thus ruling out the possibility that age and 6MWT heart rate were accounting for shared variance in MST performance. Age was included as a control variable in this analysis given prior findings of episodic memory declining with age (Old et al., 2008; Yassa et. al, 2011). However, I had not directly tested whether the relationship between age and MST performance was significant in this study. As such, I next evaluated whether age was correlated with MST performance, and a correlation 
analysis revealed that these two measures were not significantly related $(r=-0.12, p=$ 0.58). Given this lack of significance, including age as a control variable when assessing the relationship between aerobic capacity and MST performance does not appear to be necessary.

My finding of a positive association between current aerobic capacity and MST performance is in agreement with prior animal studies investigating the relationship between aerobic exercise and pattern separation (Creer et al., 2010; Bolz et al., 2015), and extends prior studies in humans that have used episodic memory tests that do not focus specifically on pattern separation (Hedden et al., 2004; Josefsson, et al., 2012).

It bears noting that, although I found a significant association between 6MWT steady state heart rate and MST performance, this relationship did not hold true when 6MWT distance was used as a measure of aerobic capacity instead of 6MWT steady state heart rate. Several factors influence 6MWT distance, including motivation, weight and height (Enright \& Sherrill, 1998; Guyatt et al.,1984), factors that are non-problematic for measures of heart rate. Thus, it would be useful for future researchers to use both measures of aerobic capacity when conducting the 6MWT.

In addition to the primary analyses described above, I also performed follow-up analyses looking at task difficulty as a predictor. Specifically, I evaluated whether the relationship between aerobic capacity and performance on the MST depended on task difficulty. I hypothesized that I would find an interaction between aerobic capacity and task difficulty, such that there would be a clear relationship between aerobic capacity and memory performance on difficult trials in which participants are required to discriminate 
between highly similar items, but that aerobic capacity would not relate to memory performance on easy trials. As expected from previous studies using the MST (Yassa et al., 2011), results indicated that performance was higher when the task was easier, i.e., when lure similarity was low. However, contrary to my predictions, results indicated that greater aerobic capacity was associated with better task performance regardless of whether lure similarity was high or low. These findings suggest that aerobic capacity is beneficial to performance on the MST overall, such that older adults with greater aerobic capacity perform better both on easier and harder trials than less fit participants.

As a secondary analysis, I also evaluated whether individual differences in MST performance were related to differences in depression symptoms, fatty acid levels (DHA and EPA), or lifetime physical activity. The regression analysis of these data was not significant. A likely contributing factor to the lack of significant findings for depression symptoms and lifetime physical activity was a lack of variability in these measures. With respect to depression symptoms, responses to the GDS were skewed, with no or little depression symptoms reported. In terms of lifetime physical activity, very few participants were categorized as extremely low or low physical activity. Additionally, it is important to note that our measure of lifetime physical activity was adapted from the Lifetime Physical Activity Questionnaire (LPAQ, Chasan-Taber et al., 2002). The LPAQ produces a measure of activity level for several individual activities (tennis, running, etc.), whereas I adapted this measure to produce a single, overall measure of activity history. This change in scoring may need further thought and development in future studies to be a more effective measure of lifetime fitness. 
Although variability in fatty acid levels, as measured by the Block FFQ (Block et al., 1986), was high, it bears noting that the FFQ was administered during the months of October, November and December, a time during which many people’s dietary habits may be unusual due to the holidays. Given that the FFQ assesses diet over the past month, it is possible that the questionnaire did not reflect participant's typical diet, and thus was not an appropriate measure.

Taken together, the results of the current study indicate that current fitness level is associated with older adults' ability to successfully engage in pattern separation, but that depression symptoms and lifestyle factors such as consumption of healthy fats and lifetime exercise history are not related to pattern separation abilities. As detailed below, however, future large-scale studies are needed to more fully characterize the relationship between measures of physical health and tests of memory that tax pattern separation. 
In general, future research into the relationship between aerobic exercise and hippocampal-dependent memory mechanisms should recruit a larger number of participants to increase power and allow for greater variability among participants, particularly in measures of depression symptoms. Studies employing the 6MWT should continue to assess heart rate data in addition to distance, the latter of which is affected by factors such as height and motivation. Future testing is also needed for researchers interested in using an adapted form of the LPAQ that produces a single measure of lifetime physical activity, or to create an easier form of the original questionnaire for older adults to use. Given that older adults may have a hard time remembering how active they were, this endeavor could be quite challenging, but nonetheless could be important to understanding the effects of lifetime physical activity on memory. Also, future research involving dietary measures should avoid collecting data during holiday seasons or should ask about dietary habits in the past year rather than in the past month to reduce atypical dietary reporting. Finally, given that our study was one of individual differences, future studies investigate whether interventions involving aerobic exercise have an impact on age-related memory decline using the same task. 


\section{References}

Beydoun, M. A., Gamaldo, A. A., Beydoun, H. A., Tanaka, T., Tucker, K. L., Talegawkar, S. A., . . . Zonderman, A. B. (2014). Caffeine and alcohol intakes and overall nutrient adequacy are associated with longitudinal cognitive performance among U.S. adults. Journal of Nutrition, 144(6), 890-891. doi:10.3945/jn.113.189027

Biagioli, B.D. (2007). Advanced concepts of personal training. United States of America: National Council on Strength \& Fitness.

Bolz, L., Heigele, S., \& Bischofberger, J. (2015). Running improves pattern separation during novel object recognition. Brain Plasticity BPL, 1(1), 129-141. doi:10.3233/bpl-150010

Block G., Hartman A.M., Dresser C.M., Carroll M.D., Gannon J., Gardner L. (1986) A data-based approach to diet questionnaire design and testing. American Journal of Epidemiology. 124(3), 453-469.

Burr, J. F., Bredin, S. S., Faktor, M. D., \& Warburton, D. E. (2011). The 6-minute walk test as a predictor of objectively measured aerobic fitness in healthy working-aged adults. The Physician and Sports Medicine, 39(2), 133-139.

Cansino, S. (2009). Episodic memory decay along the adult lifespan: A review of behavioral and neurophysiological evidence. International Journal of Psychophysiology, 71(1), 64-69. doi:10.1016/j.ijpsycho.2008.07.005

Cassilhas, R. C., Viana, V. A., Grassmann, V., Santos, R. T., Santos, R. F., Tufik, S., \& Mello, M. T. (2007). The impact of resistance exercise on the cognitive function of the elderly. Medicine \& Science in Sports \& Exercise, 39(8), 1401-1407. doi:10.1249/mss.0b013e318060111f

Cassilhas, R. C., Lee, K. S., Venâncio, D. P., Oliveira, M. M., Tufik, S., \& de Mello, M. T. (2012). Resistance exercise improves hippocampus-dependent memory. Brazilian Journal of Medical And Biological Research, 45(12), 1215-1220. doi:10.1590/S0100-879X2012007500138

Carr, V. A., Rissman, J., \& Wagner, A. D. (2010). Imaging the human medial temporal lobe with high-resolution fMRI. Neuron, 65(3), 298-308.

Center for Disease Control and Prevention. (2015a). General information about the older adult population. Retrieved May 15, 2016, from http://www.cdc.gov/aging/emergency/general.htm 
Center for Disease Control and Prevention. (2015b). How much physical activity do older adults need? Retrieved May 15, 2016, from

http://www.cdc.gov/physicalactivity/basics/older_adults/index.htm

Chapman, S. B., Aslan, S., Spence, J. S., DeFina, L. F., Keebler, M. W., Didehbani, N., \& Lu, H. (2013). Shorter term aerobic exercise improves brain, cognition, and cardiovascular fitness in aging. Frontiers in Aging Neuroscience, 5.

Chasan-Taber L., Erickson J.B., McBride J.W., Nasca P.C., Chasan-Taber S., Freedson P.S. (2002). Reproducibility of a self-administered lifetime physical activity questionnaire among female college alumnae. American Journal of Epidemiology, 155(3), 282-289.

Christensen, H., Mackinnon, A. J., Korten, A. E., Jorm, A. F., Henderson, A. S., Jacomb, P., \& Rodgers, B. (1999). An analysis of diversity in the cognitive performance of elderly community dwellers: Individual differences in change scores as a function of age. Psychology and Aging, 14(3), 365-379. doi:10.1037/0882-7974.14.3.365

Christian, K. M., Song, H., \& Ming, G. L. (2014). Functions and dysfunctions of adult hippocampal neurogenesis. Annual Review of Neuroscience, 37, 243-262.

Colcombe S.J., Kramer A.F., Erickson K.I., Scalf P., McAuley E., Cohen N.J.,...(2004). Cardiovascular fitness, cortical plasticity, and aging. Proceedings of the National Academy of Sciences of the United States of America, 101(9), 3316-21.

Creer, D. J., Romberg, C., Saksida, L. M., Praag, H. V., \& Bussey, T. J. (2010). Running enhances spatial pattern separation in mice. Proceedings of the National Academy of Sciences, 107(5), 2367-2372. doi:10.1073/pnas.0911725107

Déry, N., Pilgrim, M., Gibala, M., Gillen, J., Wojtowicz, J. M., MacQueen, G., \& Becker, S. (2013). Adult hippocampal neurogenesis reduces memory interference in humans: opposing effects of aerobic exercise and depression. Frontiers in Neuroscience, 7, 66.

Dik, M., Deeg, D., Visser, M., \& Jonker, C. (2003). Early life physical activity and cognition at old age. Journal of Clinical and Experimental Neuropsychology, 25(5), 643-653.

Duzel, E., Praag, H. V., \& Sendtner, M. (2016). Can physical exercise in old age improve memory and hippocampal function? Brain, 139(3), 662-673. doi:10.1093/brain/awv407

Elbejjani, M., Fuhrer, R., Abrahamowicz, M., Mazoyer, B., Crivello, F., Tzourio, C., \& Dufouil, C. (2015). Depression, depressive symptoms, and rate of hippocampal 
atrophy in a longitudinal cohort of older men and women. Psychological Medicine, 45(9), 1931-1944.

Enright, P. L., \& Sherrill, D. L. (1998). Reference equations for the six-minute walk in healthy adults. American Journal of Respiratory and Critical Care Medicine, 158(5), 1384-1387.

Erickson, K. I., Prakash, R. S., Voss, M. W., Chaddock, L., Hu, L., Morris, K. S., . . Kramer, A. F. (2009). Aerobic fitness is associated with hippocampal volume in elderly humans. Hippocampus, 19(10), 1030-1039. doi:10.1002/hipo.20547

Griffin, É W., Mullally, S., Foley, C., Warmington, S. A., O'mara, S. M., \& Kelly, Á M. (2011). Aerobic exercise improves hippocampal function and increases BDNF in the serum of young adult males. Physiology \& Behavior, 104(5), 934-941. doi:10.1016/j.physbeh.2011.06.005

Grundman, M., Petersen, R. C., Ferris, S. H., Thomas, R. G., Aisen, P. S., Bennett, D. A., ... \& Kaye, J. (2004). Mild cognitive impairment can be distinguished from Alzheimer disease and normal aging for clinical trials. Archives of Neurology, 61(1), 59-66.

Guyatt, G. H., Pugsley, S. O., Sullivan, M. J., Thompson, P. J., Berman, L., Jones, N. L., ... \& Taylor, D. W. (1984). Effect of encouragement on walking test performance. Thorax, 39(11), 818-822.

Hayes, S. M., Alosco, M. L., Hayes, J. P., Cadden, M., Peterson, K. M., Allsup, K., ... \& Verfaellie, M. (2015). Physical activity is positively associated with episodic memory in aging. Journal of the International Neuropsychological Society, 21(10), 780-790.

Hedden, T., \& Gabrieli, J. D. (2004). Insights into the ageing mind: A view from cognitive neuroscience. Nature Reviews Neuroscience, 5(2), 87-96. doi:10.1038/nrn1323

Josefsson, M., Luna, X., Pudas, S., Nilsson, L. G., \& Nyberg, L. (2012). Genetic and lifestyle predictors of 15-year longitudinal change in episodic memory. Journal of the American Geriatrics Society, 60(12), 2308-2312.

Kirwan, C. B., Jones, C. K., Miller, M. I., \& Stark, C. E. (2007). High-resolution fMRI investigation of the medial temporal lobe. Human Brain Mapping, 28(10), 959966.

Lacy, J. W., Yassa, M. A., Stark, S. M., Muftuler, L. T., \& Stark, C. E. (2011). Distinct pattern separation related transfer functions in human CA3/dentate and CA1 
revealed using high-resolution fMRI and variable mnemonic similarity. Learning \& Memory, 18(1), 15-18.

Leal, S. L., \& Yassa, M. A. (2015). Neurocognitive aging and the hippocampus across species. Trends in Neurosciences, 38(12), 800-812. doi:10.1016/j.tins.2015.10.003

Maass, A., Düzel, S., Goerke, M., Becke, A., Sobieray, U., Neumann, K., \& ... Düzel, E. (2015). Vascular hippocampal plasticity after aerobic exercise in older adults. Molecular Psychiatry, 20(5), 585-593. doi:10.1038/mp.2014.114

Miao-miao Zhou, Xue, Y., Shu-hong Sun, Wen, M., Zhao-jie Li, Xu, J., . . Chang-hu Xue. (2016). Effects of different fatty acids composition of phosphatidylcholine on brain function of dementia mice induced by scopolamine. Lipids in Health \& Disease, 15, 1-10. doi:10.1186/s12944-016-0305-5

Nakashiba, T., Cushman, J.D., Pelkey, K.A., Renaudineau, S., Buhl, D.L.,...Tonegawa, S. (2012) Young dentate granule cells mediate pattern separation, whereas old granule cells facilitate pattern completion. Cell 149, 188-201.

Nasreddine, Z.S., Phillips, N.A., Bédirian, V., Charbonneau, S., Whitehead, V., Collin, I.,... Chertkow H (2005). The montreal cognitive assessment (MoCA): A brief screening tool for mild cognitive impairment. Journal of the American Geriatrics Society, 53(4), 695-699.

Nokia, M. S., Lensu, S., Ahtiainen, J. P., Johansson, P. P., Koch, L. G., Britton, S. L., \& Kainulainen, H. (2016). Physical exercise increases adult hippocampal neurogenesis in male rats provided it is aerobic and sustained. The Journal of Physiology, 594(7), 1855-1873. doi:10.1113/jp271552

Norman, K. A., \& O'reilly, R. C. (2003). Modeling hippocampal and neocortical contributions to recognition memory: a complementary-learning-systems approach. Psychological Review, 110(4), 611.

Old, S. R., \& Naveh-Benjamin, M. (2008). Differential effects of age on item and associative measures of memory: a meta-analysis. Psychology and Aging, 23, 104-118. doi:10.1037/0882-7974.23.1.104

Park, D. C., Lautenschlager, G., Hedden, T., Davidson, N. S., Smith, A. D., \& Smith, P. K. (2002). Models of visuospatial and verbal memory across the adult life span. Psychology and Aging, 17(2), 299.

Petersen, R. C., Roberts, R. O., Knopman, D. S., Boeve, B. F., Geda, Y. E., Ivnik, R. J., ... \& Jack, C. R. (2009). Mild cognitive impairment: ten years later. Archives of Neurology, 66(12), 1447-1455. 
Radak, Z., Hart, N., Sarga, L., Koltai, E., Atalay, M., Ohno, H., \& Boldogh, I. (2010). Exercise plays a preventive role against Alzheimer's disease. Journal of Alzheimer's Disease, 20(3), 777-783.

Rapp, P. R., \& Amaral, D. G. (1992). Individual differences in the cognitive and neurobiological consequences of normal aging. Trends in Neurosciences, 15(9), 340-345.

Riebe, D., Franklin, B.A., Thompson, P.D., Ewing Garber, C., Whitfield, G.P., Magal, M. \& Pescatello, L.S. (2015). Updating ACSM's recommendations for exercise preparticipation health screening. Medicine \& Science in Sports \& Exercise, 47, 2473-2479.

Rosen, A. C., Prull, M. W., Gabrieli, J. E., Stoub, T., O'Hara, R., Friedman, L., \& ... deToledo-Morrell, L. (2003). Differential associations between entorhinal and hippocampal volumes and memory performance in older adults. Behavioral Neuroscience, 117(6), 1150-1160. doi:10.1037/0735-7044.117.6.1150

Sahay, A., Scobie, K. N., Hill, A. S., O'carroll, C. M., Kheirbek, M. A., Burghardt, N. S., ... \& Hen, R. (2011). Increasing adult hippocampal neurogenesis is sufficient to improve pattern separation. Nature, 472(7344), 466-470.

Sahay, A., Wilson, D., \& Hen, R. (2011). Pattern separation: A common function for new neurons in hippocampus and olfactory bulb. Neuron, 70(4), 582-588. doi:10.1016/j.neuron.2011.05.012

Shelton, D. J., \& Kirwan, C. B. (2013). A possible negative influence of depression on the ability to overcome memory interference. Behavioural Brain Research, 25(6), 20-26.

Shevtsova, O., Tan, Y. F., Merkley, C. M., Winocur, G., \& Wojtowicz, J. M. (2017). Early-age running enhances activity of adult-born dentate granule neurons following learning in rats. eNeuro, 4(4), ENEURO-0237.

Shimada, H., Park, H., Makizako, H., Doi, T., Lee, S., \& Suzuki, T. (2014). Depressive symptoms and cognitive performance in older adults. Journal of Psychiatric Research, 57, 149-156.

Smith, J. C., Nielson, K. A., Woodard, J. L., Seidenberg, M., Durgerian, S., Hazlett, K. E., . . Rao, S. M. (2014). Physical activity reduces hippocampal atrophy in elders at genetic risk for Alzheimer's disease. Frontiers in Aging Neuroscience, 6. doi:10.3389/fnagi.2014.00061 
Spalding, K. L., Bergmann, O., Alkass, K., Bernard, S., Salehpour, M., Huttner, H. B., ... \& Possnert, G. (2013). Dynamics of hippocampal neurogenesis in adult humans. Cell, 153(6), 1219-1227.

Squire, L.R., Stark, C.E.L., \& Clark, R.E. (2004). The medial temporal lobe. Annual Review Neuroscience, 27, 279-306.

Stark, S. M., Yassa, M. A., Lacy, J. W., \& Stark, C. L. (2013). A task to assess behavioral pattern separation (BPS) in humans: Data from healthy aging and mild cognitive impairment. Neuropsychologia, 51(12), 2442-2449. doi:10.1016/j.neuropsychologia.2012.12.014

ten Brinke, L. F., Bolandzadeh, N., Nagamatsu, L. S., Hsu, C. L., Davis, J. C., MiranKhan, K., \& Liu-Ambrose, T. (2014). Aerobic exercise increases hippocampal volume in older women with probable mild cognitive impairment: A 6-month randomised controlled trial. British Journal of Sports Medicine, 49(4), 248-254. doi:10.1136/bjsports-2013-093184

Treves, A., Tashiro, A., Witter, M. P., \& Moser, E. I. (2008). What is the mammalian dentate gyrus good for?. Neuroscience, 154(4), 1155-1172.

Tulving, E., \& Markowitsch, H. J. (1998). Episodic and declarative memory: Role of the hippocampus. Hippocampus, 8(3), 198-204.

U.S. Department of Health and Human services. (2008). Chapter 2: Physical activity has many health benefits. Physical Activity Guidelines for Americans. Retrieved May 8, 2017, from http://health.gov/paguidelines/guidelines/chapter2.aspx.

Varma, V. R., Chuang, Y. F., Harris, G. C., Tan, E. J., \& Carlson, M. C. (2015). Lowintensity daily walking activity is associated with hippocampal volume in older adults. Hippocampus, 25(5), 605-615.

Wilson, I. A., Gallagher, M., Eichenbaum, H., \& Tanila, H. (2006). Neurocognitive aging: prior memories hinder new hippocampal encoding. Trends in Neurosciences, 29(12), 662-670.

Weuve, J., Kang, J. H., Manson, J. E., Breteler, M. M., Ware, J. H., \& Grodstein, F. (2004). Physical activity, including walking, and cognitive function in older women. Jama, 292(12), 1454-1461.

Williams, J. G., Barnhofer, T., Crane, C., Herman, D., Raes, F., Watkins, E., \& Dalgleish, T. (2007). Autobiographical memory specificity and emotional disorder.

Psychological Bulletin, 133(1), 122-148. doi:10.1037/0033-2909.133.1.122 
Yassa, M. A., Lacy, J. W., Stark, S. M., Albert, M. S., Gallagher, M., \& Stark, C. L. (2011). Pattern separation deficits associated with increased hippocampal CA3 and dentate gyrus activity in nondemented older adults. Hippocampus, 21(9), 968979.

Yassa, M. A., \& Stark, C. L. (2011). Pattern separation in the hippocampus. Trends In Neurosciences, 34(10), 515-525. doi:10.1016/j.tins.2011.06.006

Yesavage, J. A., \& Sheikh, J. I. (1986). 9/Geriatric depression scale (GDS) recent evidence and development of a shorter version. Clinical Gerontologist, 5(1-2), 165-173. 